American Journal of Biochemistry and Biotechnology, 2012, 8 (4), 220-229

ISSN: 1553-3468

(C) 2012 A. Berenjian et al., This open access article is distributed under a Creative Commons Attribution

(CC-BY) 3.0 license

doi:10.3844/ajbbsp.2012.220.229 Published Online 8 (4) 2012 (http://www.thescipub.com/ajbb.toc)

\title{
Volatile Organic Compounds Removal Methods: A Review
}

\author{
${ }^{1}$ Aydin Berenjian, ${ }^{1}$ Natalie Chan and ${ }^{2}$ Hoda Jafarizadeh Malmiri \\ ${ }^{1}$ School of Chemical and Biomolecular Engineering, \\ Faculty of Engineering, University of Sydney, Sydney, Australia \\ ${ }^{2}$ Department of Chemical Engineering, Sahand University of Technology, Tabriz, Iran
}

Received 2012-09-24, Revised 2012-10-04; Accepted 2012-10-17

\begin{abstract}
Volatile Organic Compounds (VOCs) are among the most toxic chemicals which are detrimental to humans and environment. There is a significant need of fully satisfactory method for removal of VOCs. There are several methods including physical, chemical and biological treatments available to remove VOCs by either recovery or destruction. The aim of the present study is to summarize the available methods for VOC removal; trying to find a promising method among the available techniques. A wide range of VOCs can be treated biologically in which it offers advantages over more traditional processes including lower operating and capital costs and a smaller carbon footprint. However, due to a complex nature and diversity of VOCs it is hard to find a simple and promising method. Treatment still requires more research to solve the associate problems with available VOC elimination techniques.
\end{abstract}

Keywords: Volatile Organic Compounds (VOCs), Removal Techniques, Bio-Treatment

\section{INTRODUCTION}

Volatile Organic Compounds (VOCs) are man-made and/or naturally occurring highly reactive hydrocarbons. World Health Organisation defined VOCs as any organic compound whose boiling point is in the range from (50$\left.100^{\circ} \mathrm{C}\right)$ to $\left(240-260^{\circ} \mathrm{C}\right)$, corresponding to having saturation vapour pressures greater than $102 \mathrm{kPa}$ at $25^{\circ} \mathrm{C}$ (ISO16000-6, 1989). Many types of VOCs are toxic or even deadly to humans and can be detrimental to the environment. Therefore a multitude of definitions exist globally depending on the context frame used by Commission for Europe (UNECE) and U.S. Environmental Protection Agency (EPA).

Natural origins of VOCs include wetlands, forests, oceans and volcanoes with the estimated global VOCs biogenic emission rate at about $1150 \mathrm{Tg} / \mathrm{yr}$ (Guenther et al., 1995). A majority of VOCs are created from anthropogenic activities consisting of manufacturing industries, petrochemical industries and vehicular emissions (EPA, different organisations such as United Nations Economic

2012). Most VOCs are photo-chemically sensitive and when exposed to oxides of nitrogen and sunlight, would form ozone and other products as represented in Equation 1:

$\mathrm{NO}_{\mathrm{x}}+\mathrm{VOC}+$ Sunlight $\rightarrow \mathrm{O}_{3}+\mathrm{NO}_{\mathrm{x}}+$ other products

The reactions represented by Equation 1, involve VOCs oxidation with $\mathrm{NO}_{\mathrm{x}}$, hydroxyl catalysing some of the key reactions including other chemical compounds. Ozone formation is thus primarily driven by available nitrogen oxides and VOCs. Resulting ground level ozone formation and carcinogenic smog is the main cause of concern. As the wide range of VOCs implies a broad range of reaction rates, VOCs are capable of long range distribution and accumulation in components of environment. Efficiency of ozone formation varies with the ratio of nitrogen oxides to VOCs with higher $\mathrm{NO}_{\mathrm{X}}-\mathrm{FQUOTE} \mathrm{NO}_{\mathrm{x}}$ emissions resulting in reduced ozone production efficiency (Finlayson-Pitts and Pitts, 1986; 1999; Chanin, 1993). The isopleth plot in Fig. 1 illustrates the relation between $\mathrm{O}_{3}, \mathrm{NO}_{\mathrm{x}}$ and VOC with clear regimes of different $\mathrm{O}_{3}-\mathrm{NO}_{\mathrm{x}}$-VOC-sensitivity. Corresponding Author: Aydin Berenjian, School of Chemical and Biomolecular Engineering, Faculty of Engineering, University of Sydney, Sydney, Australia 
Dependencies vary on assumptions and conditions used during plot generation. When $\mathrm{NO}_{\mathrm{x}}$ is limited, $\mathrm{O}_{3}$ increases with increasing $\mathrm{NO}_{\mathrm{x}}$ with relatively minimal response to increasing VOC. Thus VOC control could be less effective in reducing $\mathrm{O}_{3}$ in $\mathrm{NO}_{\mathrm{x}}$ sensitive areas e.g., rural areas and downwind from the source (Finlayson-Pitts and Pitts, 1986).

In the limited VOC regime to the left of the ridge line, lowering VOC concentrations result in lower peak ozone concentrations. Contradictory lowering $\mathrm{NO}_{\mathrm{x}}$ at constant VOC concentrations predicts increased peak ozone concentrations to the ridge line. This is due to more hydroxyl radicals available to react with VOCs due to reduced $\mathrm{NO}_{\mathrm{x}}$-hydroxyl reactions. Only past the ridge line does the ozone concentration begin to decease. Ozone concentrations are also lowered by proportionately decreasing both VOCs and $\mathrm{NO}_{\mathrm{x}}$ concentrations simultaneously (Dodge, 1977; Finlayson-Pitts and Pitts, 1986). Thus, Fig. 1 emphasises there is greater benefit in reducing VOC concentrations over $\mathrm{NO}_{\mathrm{x}}$ for optimal ozone control strategies closer to the source of emission.

VOCs are not only outdoor pollutants as high concentrations have been recorded indoors as well. Indoor sources include solvents used in the production and maintenance of building materials, furnishings or equipment e.g., paint, carpets, plastics and photocopying machines. The National Health and Medical Research Council (NHMRC) interim national indoor air quality recommends a maximum hourly average total VOC level of $500 \mu \mathrm{g} \mathrm{m} \mathrm{m}^{-3}$, where each compound should not contribute more than $50 \%$ of the total (NHMRC, 2002). In a study investigating VOC emissions from office furniture, a range of major VOCs emitted over time was found to be in excess of the NHMRC recommendation. Formaldehyde was found to be emitted in high concentrations from furnishings using reconstituted wood-based panels e.g., particleboards, medium-density fibreboard (NHMRC, 2002). Table 1 details the results for major VOCs emitted by new office furniture.

Indoor levels of VOC can be regulated by selecting low-emission materials for furnishing, cleaning and construction. This approach is impractical as many of the materials emitting VOCs are considered standard fixtures and attempting to replace them could prove costly. Furthermore, proper ventilation with outdoor air can help in managing air pollutants indoors by means of dilution. However with the increasing number of highrise buildings developing in major cities, the problem of VOC pollution becomes both an indoors and outdoors issue that requires a permanent solution (Guo et al., 2004; Alvarez-Hornos et al., 2008).

Various traditional VOCs removal and elimination technologies exist. In the present study we summarize the available methods for VOCs removal; try to find a promissing technique.

\subsection{Common VOCs Removal Methods}

There are physical, chemical and biological treatments available to remove VOCs from air by either recovery or destruction. The contaminated liquid can be aerated either via packed tower aeration or mechanical surface aeration with VOC emissions captured and treated. Traditional primary removal solutions for VOCcontaminated liquids are liquid-phase activated carbon adsorption or air stripping. For soil VOC contamination remediation, Soil Vapour Extraction (SVE) is used (EPA, 1991; Tchobanoglous and Kreith, 2002). These methods allow for the extraction of VOCs into another phase.

In liquid-phase activated carbon adsorption, the treated liquid is put in physical contact with activated carbon to allow dissolved organic contamination to bind to it. The activated carbon can be either regenerated or removed after treatment (DOE, 1994). Reactors commonly used for this process are the fixed bed and the pulsed/moving bed. When dealing with halogenated VOCs and pesticides, this carbon method has limited effectiveness. Economical and logistical issues would arise from disposing or decontaminating the spent carbon, hence carbon adsorption is applied more effectively for "polishing" post-treated liquid discharges with low VOC concentrations (EPA, 1990; 1993; 1995). Similarly VOCs in air emission can be treated with activated carbon by pumping it through activated carbon packed bed reactors. However, problems with spent carbon are the same as the liquid-phase carbon method.

Common permanent solutions to treat extracted VOC emissions would be through oxidation by thermal, internal combustion engine, catalytic or UV. Essentially VOCs are broken down into less harmful compounds such as carbon dioxide, water and hydrochloric gas.

Thermal oxidation units are generally single chambers with ceramic blanket refractory lining the oxidisers, equipped with a propane or natural gas burner and a stack. In the chamber, burner capacities range between 0.4 to 2 (mil BTUs) $/ \mathrm{hr}$ with operating temperatures from 760 to $870^{\circ} \mathrm{C}$ and a maximum gas residence time of $1 \mathrm{sec}$. The internal combustion engine works in the same way; however, it is adapted to high VOC concentrations to allow the organic compounds to be used as fuel. Auxiliary fuel is only added to enhance oxidation. To reduce the need for auxiliary fuel, air to air heat exchangers can be used to transfer heat from the exhaust gases to the incoming feed. In treating halogenated VOCs, the exhaust stream would require a gas scrubber to control the acid vapour (Benitez, 1993). Oxidation is deemed inefficient for low VOCs concentrations in the range of between 0.1 to $10 \mathrm{~g} \mathrm{Mm}^{-3}$ as continuous oxidation is difficult to maintain unless with more supporting fuel (Rao, 2007). 


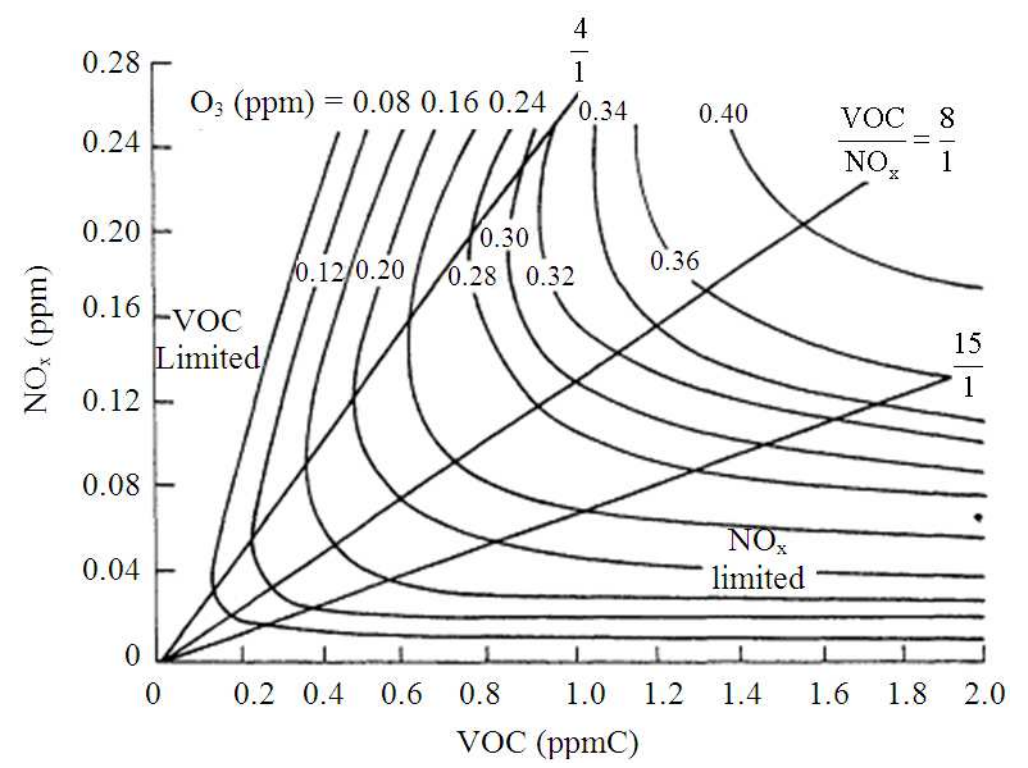

Fig. 1. General ozone isopleth used in EPA's, Empirical Kinetic Modelling Approach (EKMA) modelled against ratios found in cities (Dodge, 1977)

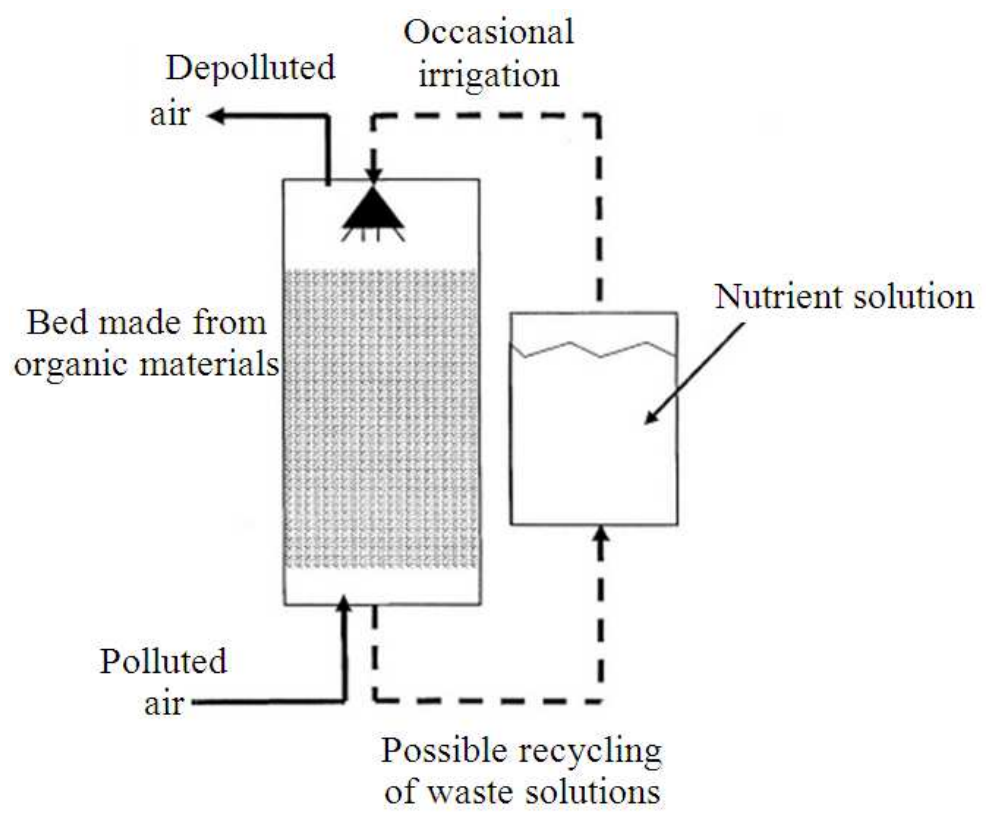

Fig. 2. Schematic diagram of a biofilteration unit (Delhomenie and Heitz, 2005)

Catalytic oxidation involves the addition of a catalyst to a thermal oxidiser to accelerate oxidation via the adsorption and reaction of oxygen and organic compounds on the catalyst surface. This lowers the reaction temperature to a range between 320 to $540^{\circ} \mathrm{C}$ compared to that required in a conventional thermal oxidiser. The direct pre-heating of feed to the reaction temperature is required to initiate catalytic oxidation when passed through a solid catalyst bed. Catalysts may contain various metal oxides such as chromium oxide or nickel oxide and may even contain noble metals e.g., palladium. 
Aydin Berenjian et al. / American Journal of Biochemistry and Biotechnology 8 (4) (2012) 220-229

Table 1. Formaldehyde and VOC concentrations and emission factors from new office furniture (Brown, 1999)

\begin{tabular}{|c|c|c|c|c|}
\hline \multirow[b]{2}{*}{ VOC } & \multicolumn{2}{|c|}{ Concentration $\left(\mu \mathrm{g} / \mathrm{m}^{3}\right)$} & \multicolumn{2}{|c|}{ Emission Factor $\left(\mu \mathrm{g} / \mathrm{m}^{2} . \mathrm{h}\right)$} \\
\hline & $4 \mathrm{~h}$ & $24 \mathrm{~h}$ & $4 \mathrm{~h}$ & $24 \mathrm{~h}$ \\
\hline Formaldehyde & 190 & 230 & 240 & 290 \\
\hline Freon 22 & 42 & 700 & 530 & 890 \\
\hline Methanol & 4000 & 2700 & 5000 & 3400 \\
\hline Acetone & 450 & 254 & 560 & 320 \\
\hline Butanal & 290 & 220 & 360 & 280 \\
\hline Ethylacetate & 660 & 580 & 830 & 730 \\
\hline Methyl isobutyl ketone & 200 & 210 & 250 & 260 \\
\hline Hexanal & 28 & 23 & 35 & 29 \\
\hline $\mathrm{m}$ - and p-Xylene & 59 & 48 & 74 & 60 \\
\hline Cyclohexanone & 55 & 54 & 69 & 68 \\
\hline Phenol & 180 & 90 & 230 & 110 \\
\hline Total VOC & 970 & 820 & 200 & 1030 \\
\hline
\end{tabular}

Thermal oxidisers can be used as pre-treatment to catalytic units for high VOC concentrations (EPA, 1987; Benitez, 1993; Rao, 2007; Berenjian and Khodiev, 2009; Berenjian et al., 2011).

UV oxidation method has been used to oxidise organic and explosive compounds in wastewater. Strong chemical oxidisers directly react to the contaminants with UV photolysis achieved through synergistic UV irradiation combined with ozone and/or hydrogen peroxide (Christman and Collins, 1990; EPA, 1990). Generally low pressure $65 \mathrm{~W}$ lamps are used for ozone treatment systems and $15-60 \mathrm{~W}$ lamps are used in hydrogen peroxide treatment. Final products of UV oxidation are carbon dioxide, water and salts. Although, able to treat a wide range of VOCs, certain contaminants may be volatilised rather than destroyed e.g., TCA. In such a case, post treatment by activated carbon adsorption may be required (Zappi et al., 1992).

Bio-treatment of VOCs is a relatively less established VOC removal method; however, it offers possible advantages over more traditional processes with lower operating and capital costs and a smaller carbon footprint. This is due to lower energy requirements as microorganisms are used to metabolise organic compounds at ambient temperature instead being dependent on heat or radiation. Since 1923, gas biofiltration has been applied to treat various VOC exhaust contaminants (Leson and Smith, 1997; Wieczorek, 2005). Biological methods include bio-filters, biotrickling filters, bio-scrubber, suspended growth reactors and membrane bio-reactors (Doble and Kumar, 2005). Key parameters across bio-systems are identified as moisture content in the medium, temperature, $\mathrm{pH}$ and availability of essential and non-carbon nutrients (Leson and Winer, 1991; Swanson and Loehr, 1997; Sidkar and Irvine, 1998). As a wide range of VOCs are biodegradable, they can be treated biologically with organisms matched to the type of VOC to be destroyed. Some easily biodegradable VOCs are esters, benzene, toluene and phenols. Due to future growth potentials for the use of biofiltration methods, these methods are detailed and expanded upon in the following sections.

\subsection{Bio-Treatment}

Bio-technologies effectively and economically treat contaminated air flows from 60 to $150,000 \mathrm{~m}^{3} / \mathrm{h}$ with lower VOC concentrations than most other available technologies. This advantage enables it to be applied to smaller scale projects such as possibly retro-fitting building ventilations with a compact VOC treatment system. Existing bio-treatment of VOCs used in gas treatment revolves around the concept of bio-filtration. There are various other bio-filtration processes available such as Bio-Trickling Filters (BTFs), bio-scrubbers and newer technology e.g., bio-membrane bioreactors (Cox and Deshusses, 1998; Doble and Kumar, 2005). Biofiltration is generally based on two principals: firstly, the transfer of pollutants from the air feed to the support medium. Secondly, the contaminants are bio-catalysed to biomass, carbon dioxide, water and other by-products (Miller and Allen, 2004). Schematic diagram of a biofilteration unit is shown in Fig. 2.

The traditional bio-filteration system is essentially a fixed-bed bioreactor where the bio-catalyst or microorganism is immobilised to an inert supporting medium to develop biofilms. Ideal packing bed materials have high void fraction, light weight, low pressure drop, hydrophilic and low bulk density. Occasional irrigation of nutrient solution onto the packing bed and humidity control maintains the biofilms. Polluted air is fed from the bottom through the porous biologically-active media, where pollutants diffuse into the aqueous-phase or are absorbed directly by the biofilm with treated air emitted 
from the top. Unfortunately, VOCs containing sulphates, chlorides and nitrates have acidic by-products that can adversely affect the ecosystem and reduce the effectiveness of the bioreactor (Garner and Barton, 2002).

The biotrickling filter has gas flowing through a fixed bed with microorganisms immobilised through it. Ideal packing material is similar to the traditional set up. Nutrient solution is continuously irrigated from the top, collected at the bottom and recycled back up. Co-current or counter-current flow between the gaseous and aqueous phases was found to have no influence on the degradation performance (Cox and Deshusses, 1998). The biotrickling system allows for more efficient removal of soluble VOCs from the air stream as well as enabling feedback control for nutrient levels and $\mathrm{pH}$. As there is a constant feed of nutrients to the system, excess biomass builds up quickly and can lead to performance loss and pressure drops from uneven biomass distribution (Cohen, 2001).

Bioscrubbers consist of an absorption tower and a bioreactor. In the absorption tower, gas phase contaminants are diffused into an aqueous solution via means of counter-current gas-liquid flows through inert packing. The washed gas is emitted from the top and the contaminated liquid pumped towards an aerated bioreactor. The microorganism or activated sludge in the reactor is suspended in a nutrient-rich media and residence time for treatment varies according to the type and concentration of VOCs in the feed. After completed degradation of contaminants, the medium is filtered and biomass left to sediment with portions being recycled through the bioscrubbing process again. An aqueous system with no high pressure drops allows for more evenly distributed temperature, nutrient and $\mathrm{pH}$ controls. System limitations are due to the narrow band of VOCs treatable. This range is limited by water solubility of contaminants thus only applying to organics with low Henry's coefficient $(<0.01)$ at low concentrations $\left(<5 \mathrm{~g} / \mathrm{m}^{3}\right)$. Compared to other bioreactors considered, the bioscrubber requiring two sub-units could be a space limitation; especially when multiple systems in series or parallel are required to process higher VOC volumes. Bioscrubbers, however, are not as well-utilised within the biotechnology market compared to biofilters and biotricklers (Swanson and Loehr, 1997). To treat lesssoluble pollutants, silicon oil could be added to aqueous systems as an emulsifying agent to favour the VOC mass transfer from gas to liquid phases.

Finally, membrane bioreactors involve a membrane partitioning the liquid and gas phases. The nutrient and biomass growth is within the liquid side whilst the gaseous contaminants are pressurised to induce diffusion over the partition into the aqueous solution. The membranes can be further treated to have various advantageous properties e.g., hydrophobic and microporous. Membrane bioreactors for VOC treatment still require more research to minimise fouling and high cost (Artiga et al., 2005).

\subsection{Operating Parameters}

The operations of biofilters involve a series of steps beginning with the transfer of the pollutant air to the aqueous phase, followed by its adsorption onto the medium or absorption into the biofilm and then biodegradation of VOCs within the biofilm (Kumar et al., 2011). The biodegradation of pollutants by biofilms in biofiltration sytem is a combination of physicochemical and biological phenomena. Basically these three mechanisms are responsible for the transfer and subsequent biodegradation within the bed (Doble and Kumar, 2005; Mathur et al., 2006).

Governing control parameters across all bioreactors includes packing material, air flow rate, temperature (Darlington et al., 2001), pH, humidity and non-carbon nutrients e.g., nitrogen, phosphate and potassium (VanLith et al., 1997; Devinny et al., 1999). However, as the type of microorganism used is dependent on the type of VOC to be destroyed, treating a wide range of VOCs in indoor air would result in a diverse ecology of mixed fungal and bacterial populations (Khammar et al., 2005). This diversity creates complex interactions within the bioreactors which require research into the ecology of the biomass to optimise overall management of the ecosystem.

\subsection{Packing/Filter Bed}

As the filter bed physically supports the entire biosystem, some of the criteria required to achieve optimal conditions are high-specific surface area which is excellent for microbial activity, decent water retention capacity and high porosity. Basic traditional organic materials used for packing are peats, composts and soils because of their stability, low cost and effectiveness (Doble and Kumar, 2005). Modern approaches enable beds to have evenly-distributed rigid structures preventing bed compaction. Furthermore, biocatalysts can be immobilised within a porous structure (polymer beads) to allow for easier maintenance and preservation of specific microorganisms ( $\mathrm{Lu}$ et al., 2002). Pressure drop of the filter bed is an important biofiltration parameter which drastically effects on operating cost. Filter beds including small particles have high specific 
surface area which in turn make them suitable for microbial activity and increase their resistance to air flow (Kumar et al., 2011).

\subsection{Flow Rate}

In general, overall efficiency of biofilters is related to two main microscopic processes. The first process is transfer rate of the VOCs from gas phase to biofilm and the second one is biodegradation rate of VOCs (Delhomenie and Heitz, 2005). The air flow rate is an important parameter which can affect both of these processes. In fact, by increasing the flow rate, the rates of VOCs transfer to the biofilm and degradations decrease. This can be explained by the fact that in extremely high air flow rates, contact times between microorganisms and gases are too short and the biodegradation reaction cannot be completed (Cox and Deshusses, 1997). The Empty Bed Residence Time (EBRT) is defined as a time that parcel of air will remain in the biofilter and calculated as the empty bed filter volume divide by the air flow rate. Several studies have shown that to improve biofiltration performance and better VOCs removal efficiency, the EBRT should be greater than the time required for diffusion process (Doble and Kumar, 2005; Kumar et al., 2011). It has been reported that by increasing the size of particles in the filter beds, the resistance of filter beds decrease towards gas flow (Clark et al., 2004).

\subsection{Temperature}

Operating temperature is one important factor that affects biofilter performance. The microorganisms that most effectively degrade VOC compounds in biofilters are mesothermic and their optimum activity temperatures are between 30 and $40^{\circ} \mathrm{C}$ (Clark et al., 2004). In fact, the proper temperature increases the rate of biofilm development and biomass accumulation (Yang et al., 2010). Deeb and Alvarez-Cohen (1999) indicated that in the optimum range of operating temperature, the degradation performance on biofilter can increase 2fold by $10^{\circ} \mathrm{C}$ increase in temperature. This can be explained by the fact that by rising the temperature, VOCs and $\mathrm{O}_{2}$ solubilise in water decrease and diffusion transfer increases. Due to exothermic nature of the biodegradation reactions, the variation of temperature in the filter bed is a consequence of microbial activity (Hwang et al., 2002).

\section{7. pH}

For most bioreactors, $\mathrm{pH}$ has a significant impact on biofiltration efficiency. The $\mathrm{pH}$ of the biofilteration medium can have direct effect on microorganisms and microbial enzymes and also indirect influence on the availability of required nutrients. In fact, depending on the type of microorganism the $\mathrm{pH}$ has significant effect on the biofiltration efficiency (Clark et al., 2004; Delhomenie and Heitz, 2005). Fungi are able to grow under both neutral as well as acidic conditions and are metabolically active over a wide $\mathrm{pH}$ range between approximately 2 and 7 . Whereas bacteria are usually considered to be less tolerant to $\mathrm{pH}$ fluctuations and require a near neutral environment for their activity (Kennes and Veiga, 2004). Due to neutrophilic behaviour of the most of microorganisms in biofilters, maximum degradation of VOCs would usually be achieved at $\mathrm{pH}$ around 7 (Kumar et al., 2001). Veiga et al. (1999) studied the effect of $\mathrm{pH}$ on alkyl benzene degradation (between pH 3.5 and 7.0) and found that alkyl benzene degradation increases with $\mathrm{pH}$ increase. Lu et al. (2002) reported the maximum degradation for BTEX between $\mathrm{pH}$ values of 7.5 and 8.0. However, the ideal $\mathrm{pH}$ of the biofilter medium depend on the pollutant being treated and the characteristics of the microbial ecosystem.

\subsection{Moisture}

The moisture content of the filter bed plays an important role in biofilter performance because microorganisms need water to attain their metabolic activity (Kumar et al., 2011). Availability of excess water hinders the transfer of oxygen and hydrophobic pollutants to the biofilm, leading to the development of anaerobic zones within the bed. It also leads to the reduction of the specific surface available for gas/biofilm exchanges, which in turn, causes bed compaction and increasing the pressure drop. Too low bed moisture content leads to bed desiccation and gas flow channeling, which particularly affects the microflora (Delhomenie and Heitz, 2005). The support of microbial populations sufficient to reduce VOCs requires that moisture levels in the filter medium be maintained between $40 \%$ and $70 \%$ (w.b.) (Clark et al., 2004). The main factors affecting the bed moisture content are gas flow rate through the bed, water holding capacity of the filtering materials, reaction exothermicity and inlet gas relative humidity (Devinny et al., 1999).

\subsection{Microorganism}

Microorganisms including bacteria and fungi are used in VOCs biodegradation methods. Researchers have indicated that heterotrophic bacteria and fungi are the main microorganisms used in elimination of VOCs (Delhomenie and Heitz, 2005). However, the main 
advantage of fomenting fungal rather than bacterial growth for the biofiltration of hydrophobic pollutants is their ability to degrade the substrates under extreme environmental conditions regarding $\mathrm{pH}$, low water content and limited nutrient concentrations (Kennes and Veiga, 2004). Generally, heterotrophic microbial strains used in VOC bioreactors, can bio-catalyse VOCs via two pathways: (1) consuming organic compounds in the course of catabolic pathway for energy or (2) using VOCs as a carbon source for anabolic processes. Species of Pseudomonas, Candida, Mycobacterium, Alcaligenes, Exophiala, Acetinobacter, Fusarium, Cladosporium, Rhodococus, Aspergillus and mucor are some of microorganisms which identified and used for degradation of VOCs by biofiltration (Marek et al., 1999; Diehl et al., 2000; Christen et al., 2002; Qi et al., 2002; Woertz et al., 2002). The filter bed inoculation depends on both the nature of the filtering materials and the VOC biodegradability level. Generally, a biofilter contains between $10^{6}$ and $10^{10} \mathrm{cfu}$ of bacteria and actinomycetes per gram of bed, respectively. It can also contains $10^{3}$ to $10^{6}$ spores of fungi per gram of bed (Delhomenie and Heitz, 2005).

\subsection{Biomass}

Biofilm is a complex aggregation of microorganisms (aerobic, anaerobic and facultative type bacteria, fungi, algae and protozoa) which attach themselves on the surface of the packing media and forms a biological film or slim layer with a viscous slimy structure (Kumar et al., 2011). There are three main biological processes that occur in the biofiltration systems, namely: attachment of microorganisms, growth of microorganisms and decay and detachment of microorganisms (Yang et al., 2010).

Assuming the biofilm is built on water, Henry's Law represented in Equation 2 roughly estimates maximum concentrations of aqueous pollutant $\left(\mathrm{C}_{\mathrm{aq}}^{*}\right)$ available to be bio-catalysed:

$$
\mathrm{C}_{\mathrm{aq}}^{*}=\frac{\mathrm{p}_{\mathrm{i}}}{\mathrm{H}_{\mathrm{i}}}
$$

where, $p_{i}$ represents the partial pressure of a specific pollutant in gaseous phase and $\mathrm{H}_{\mathrm{i}}$ is Henry's constant coefficient of the pollutant. This model of estimation, however, does not in fact express the transport and reaction processes of the biomass itself. Waterinsoluble compounds such as $\alpha$-pinene have been found to be significantly removed by biofilm (VanGroenestijn and Liu, 2002). Upon comparison, the $\alpha$-pinene partitioning of biofilm containing biomass and organics was also found to be greater than biofilm in water (Miller and Allen, 2004).

As the dominant carbon source, the VOC gas supply for the biotrickling filter creates a gradient of high specific biomass growth rates starting from the feed inlet and tapering off towards the outlet (Song and Kinney, 1999). In a gas-phase biofilter, biomass accumulation rate is equal to the biofilm growth rate minus the biofilm decay rate resulting from hydraulic scouring or detachment. Thus, allowing for general modelling of biofilm thickness over time to be calculated from bacterial growth and decay as shown in Equation 3 and 4 (Alonso et al., 1997; 1998):

$$
\begin{aligned}
& \frac{\partial L f}{\partial t}=\left(\left.r_{d} D_{w} \frac{\partial C_{f}}{\partial x}\right|_{x=L}\right) \frac{Y}{X_{f}}-L_{f} b \\
& b=b_{s}+b_{d}
\end{aligned}
$$

Where:

$\mathrm{L}_{\mathrm{f}}=$ Biofilm thickness

$r_{d}=$ Ratio between VOC diffusivities in biofilm and water

$\mathrm{D}_{\mathrm{w}}=$ Contaminant diffusivity in water

$\mathrm{C}_{\mathrm{f}}=$ VOC concentration in biofilm

$\mathrm{Y}=$ Yield coefficient

$\mathrm{X}_{\mathrm{f}}=$ Film bacterial density

$\mathrm{b}=$ Specific shear/decay coefficient

$b_{\mathrm{d}}=$ Specific decay coefficient

$\mathrm{b}_{\mathrm{s}}=$ Specific shear rate

Other factors such as oxygen availability, carbon source and biofilm activity all interact to affect the biofilm decay rate. Factors contributing to shear force could result from calculating in fluid flow or particle attrition as well. This general model of prediction would enable biomass controls to be set in place to prevent a drop in efficiency from excess biomass. There are five methods of control including physical, chemical, biological, improved biofilter designs and improved operation modes. Most physical treatments involve bed stirring or backwashing to drain excess accumulated biomass. Chemical controls can be put on the carbon and nutrient sources to starve the biofilm. Periodical starvation does not affect removal performance in biotrickle reactors as microorganisms degrade their own extracellular polymers for energy (Zhang and Bishop, 2003). Chemical washing of the biofilter to control 
biomass could have a detrimental effect on performance and requires time to reacclimatise. It must be noted that to achieve higher bio-conversion efficiency, the bio-filter should be exposed to low VOC concentrations initially to allow culture adaption to utilising VOCs as a carbon source. Following which, the organic loading can be increased over time.

\subsection{Overview of Using Biological Treatments}

As previously detailed, the four most common types of biological treatment units are biofilter, biotrickling filter, membrane bioreactor and bioscrubber. These systems have differences in their complexity, process design, equipment dimensions and working parameters, but they have unique advantages which make them proper techniques to remove wide range of compounds. Biofilters have advantages such as low initial investment and subsequently minimized operating cost, degradation a wide range of components, easy to operate and maintain, no production of unnecessary waste streams and low pressure drop (Yang et al., 2010). Biotrickling filters have less operating and capital constraints, less relation time/high volume through put and capability to treat acid degradation product of VOCs (Cox and Deshusses, 1998). In membrane bioreactors there are no moving parts, process scale up is more easy and flow of gas and liquid can be varied independently, without the problems of flooding, loading or foaming (Artiga et al., 2005). Bioscrubbers need relatively smaller space requirements and able to deal with high flow rates and severe fluctuations. Other advantages of using this system can be mentioned as operational stability, better control of operating parameters and relatively low pressure drop (Swanson and Loehr, 1997).

Applications of biological systems to remove VOCs have some limitations. For example, limitations of using biofilters are less treatment efficiency at high concentrations of pollutants, extremely large size of bioreactor challenges space constraints to require close control of operating conditions and limited life of packing and clogging of the medium due to particulate medium (Delhomenie and Heitz, 2005). Accumulation of excess biomass in the filter bed, requirement of design for fluctuating concentration, complexity in construct and operation and secondary waste stream are among the disadvantages of using biotrickling filters (Cox and Deshusses, 1997; Doble and Kumar, 2005). Limitations of application of membrane bioreactors to removal VOCs are high construction costs, long-term operational stability and possible clogging of the liquid channels due the formation of excess biomass (Doble and Kumar,
2005). Some disadvantages of using bioscrubbers are treatment of only water soluble compounds, generation of liquid waste, need of extra air supply, need of excess sludge disposal and operation/maintenance complicities (Kumar et al., 2011).

\section{CONCLUSION}

Based on the present study, biological methods (biofilter, biotrickling filter, membrane bioreactor and bioscrubber) can be used as potential methods for VOCs removal as compared to the other available elimination techniques. However, use of biological systems to remove VOCs still have limitations and challenges. These systems do not response well to sudden loading stresses and can fail. Due to detrimental nature of VOCs to humans and environment, more practical and more efficient VOC removal techniques are in demand. A combination of existing treatments can be considered as another approach which may help to increase VOCs treatment effectiveness at higher concentrations, whilst reducing costs e.g., biofiltration as a post-treatment to adsorption.

\section{REFERENCES}

Alonso, C., M.T. Suidan, B.R. Kim and B.J. Kim, 1998. Dynamic mathematical model for the biodegradation of VOCs in a biofilter: Biomass accumulation study. Environ. Sci. Technol., 2: 3118-23. DOI: 10.1021/es9711021

Alonso, C., M.T. Suidan, G.A. Sorial, F.L. Smith and P. Biswas et al., 1997. Gas treatment in trickle-bed biofilters: Biomass, how much is enough. J. Biotechnol. Bioeng., 54: 583-594. PMID: 18636414

Alvarez-Hornos, F.J., C. Gabaldon, V. Martinez-Soria, M. Martin and P. Marzal et al., 2008. Biofiltration of ethylbenzene vapours: Influence of the packing material. Biores. Technol., 99: 269-276. PMID: 17317157

Artiga, P., V. Oyanedel, J.M. Garrido and R. Mendez, 2005. An innovative biofilm-suspended biomass hybrid membrane bioreactor for wastewater treatment. Desalination, 179: 171-179. DOI: 10.1016/j.desal.2004.11.065

Benitez, J., 1993. Process Engineering and Design for Air Pollution Control. 1st Edn., PTR Prentice Hall, Englewood Cliffs, ISBN-10: 0137232144, pp: 466.

Berenjian, A. and A. Khodiev, 2009. How ozone can affect volatile organic compounds. Australian J. Basic Applied Sci., 3: 385-388. 
Berenjian, A., A. Fathi, S. Feghenabi and A. Khodiev, 2011. Complete removal of toluene from Air: A response surface methodology. Australian J. Basic Applied Sci., 5: 286-288.

Brown, S.K., 1999. Chamber assessment of formaldehyde and VOC emissions from wood-based panels. Indoor Air, 9: 209-215. PMID: 10439559

Chanin, M.L., 1993. The Role of the Stratosphere in Global Change. 1st Edn., Springer, Berlin, ISBN: 10-3540568433, pp: 557.

Christen, P., F. Domenech, G. Michelena, R. Auria and S. Revah, 2002. Biofiltration of volatile ethanol using sugar cane bagasse inoculated with Candida utilis. J. Hazardous Mater., 89: 253-265. DOI: 10.1016/S0304-3894(01)00314-4

Christman, P.L. and A.M. Collins, 1990. Treatment of organic contaminated groundwater by using ultraviolet light and hydrogen peroxide. Proceedings of the Annual Army Environmental Symposium, (AAES, 90).

Clark, O.G., I. Edeogu, J. Feddes, R.N. Coleman and A. Abolghasemi, 2004. Effects of operating temperature and supplemental nutrients in a pilotscale agricultural biofilter. Canadian Biosyst. Eng., 46: 7-16.

Cohen, Y., 2001. Biofiltration- the treatment of fluids by microorganisms immobilized into the filter bedding material: A review. Bioreso. Technol., 77: 257-274. DOI: 10.1016/S0960-8524(00)00074-2

Cox, H.H.J. and M.A. Deshusses, 1997. The use of protozoa to control biomass growth in biological trickling filters for waste air treatment. Proceeding of Annual Meeting and Exhibition of the Air and Waste Management Association, (AMEAWMA' 97), Pittsburgh, PA.

Cox, H.H.J. and M.A. Deshusses, 1998. Biological waste air treatment in biotrickling filters. Curr. Opin. Biotechnol., 9: 256-62. DOI: 10.1016/S09581669(98)80056-6

Darlington, A.B., J.F. Dat and M.A. Dixon, 2001. The biofiltration of indoor air: Air flux and temperature influences the removal of toluene, ethylbenzene and xylene. Environ. Sci. Technol., 35: 240-246. DOI: $10.1021 / \mathrm{es} 0010507$

Deeb, R.A. and L. Alvarez-Cohen, 1999. Temperature effects and substrate interactions during the aerobic biotransformation of BTEX mixtures by tolueneenriched consortia and rhodococcus rhodochrous. Biotechnol. Bioeng., 62: 526-536. PMID: 10099561

Delhomenie, M.C. and M. Heitz, 2005. Biofiltration of air: A review. Critical Revi. Biotechnol., 25: 53-72. DOI: $10.1080 / 07388550590935814$
Devinny, J.S., M.A. Deshusses and T.S. Webster, 1999. Biofiltration for Air Pollution Control. 1st Edn., Lewis Publishers, Boca Raton, ISBN-10: 1566702895, pp: 299.

Diehl, S.V., B. Saileela, L.L. Wasson and A. Borazjani, 2000. Biofiltration of selected monoterpenes found in southern yellow pine wood emissions. Forest Products J. Index, 50: 43-48.

Doble, M. and A. Kumar, 2005. Biotreatment of Industrial Effluents. 1st Edn., ButterworthHeinemann, ISBN-10: 0750678380, pp: 336.

Dodge, M.C., 1977. Combined use of modeling techniques and smog chamber data to derive ozoneprecursor relationships. Proceedings of the International Conference on Photochemical Oxidant Pollution and its Control, (POPC' 77), U.S. Environmental Protection Agency, Research Triangle Park, NC., pp: 881-889.

DOE, 1994. Technology application analysis: Petroleum product recovery and contaminated groundwater remediation amoco petroleum pipeline constantine.

EPA, 1987. Destruction of organic contaminants by catalytic oxidation.

EPA, 1990. Innovative and alternative technology assessment manual. Office of Water Program Operations, EPA.

EPA, 1991. Soil vapour extraction technology: Reference handbook. Office of Research and Developmen, $\mathrm{OH}$.

EPA, 1993. Approaches for the remediation of federal facility sites contaminated with explosive or radioactive wastes.

EPA, 1995. Remediation case studies: Groundwater treatment. Federal Remediation Technologies Roundtable.

EPA, 2012. Volatile Organic Compounds (VOCs).

Finlayson-Pitts, B.J. and J.N. Pitts, 1986. Atmospheric Chemistry: Fundamentals and Experimental Techniques. John Wiley and Sons, New York, ISBN-10: 0471882275, pp: 1098.

Finlayson-Pitts, B.J. and J.N. Pitts, 1999. Chemistry of the Upper and Lower Atmosphere. 1st Edn., Academic Press, San Diego, ISBN-10: 9780122570605, pp: 969.

Garner, L.G. and T.A. Barton, 2002. Biofiltration for abatement of VOC and HAP emissions. Metal Finish., 100: 12-18. DOI: 10.1016/S00260576(02)80931-X

Guenther, A., C.N. Hewitt, D. Erickson, R. Fall and C. Geron et al., 1995. A global model of natural volatile organic compound emissions. J. Geophysical Res., 100: 8873-8892. DOI: 10.1029/94JD02950 
Guo, H., S.C. Lee, L.Y. Chan and W.M. Li, 2004. Risk assessment of exposure to volatile organic compounds in different indoor environments. Environ. Res., 94: 57-66. DOI: 10.1016/S00139351(03)00035-5,

Hwang, S.C.J., S.J. Wu and C.M. Lee, 2002. Water transformation in the media of biofilters controlled by rhodococcus fascians in treating an ethyl acetatecontaminated airstream. J. Air Waste Manage. Assoc., 52: 511-520. DOI: 10.1080/10473289.2002.10470804

ISO16000-6, 1989. Volatile organic compounds in air analysis.

Kennes, C. and M.C. Veiga, 2004. Fungal biocatalysts in the biofiltration of VOC-polluted air. J. Biotechnol., 113: 305-319. DOI: 10.1016/j.jbiotec.2004.04.037

Khammar, N., L. Malhautier, V. Degrange, R. Lensi and J.J. Godon et al., 2005. Link between spatial structure of microbial communities and degradation of a complex mixture of volatile organic compounds in peat biofilters. J. Applied Microbiol., 98: 476490. DOI: $10.1111 /$ j.1365-2672.2004.02474.x

Kumar, T.P., M. Rahul, A. Kumar and B. Chandrajit, 2011. Biofiltration of Volatile Organic Compounds (VOCs)-An overview. Res. J. Chem. Sci., 1: 83-92.

Leson, G. and A. Winer, 1991. Biofiltration: An innovative air pollution control technology for VOC emissions. J. Air Waste Manage. Assoc., 41: 10451054. PMID: 1958341

Leson, G. and B.J. Smith, 1997. Petroleum environmental research forum field study on biofilters for control of volatile hydrocarbons. J. Environ. Eng., 123: 556-562. DOI: 10.1061/(ASCE)0733-9372(1997)123:6(556)

Lu, C., M.R. Lin and C. Chu, 2002. Effects of pH, moisture and flow pattern on trickle-bed air biofilter performance for BTEX removal. Adv. Environ. Res., 6: 99-106. DOI: 10.1016/S10930191(00)00072-1

Marek, J., B. Massart, A. Robson, X. Nicolay and J. P. Simon, 1999. Gel entrapped cells for waste gas biofiltration. Institut Meurice, Bruxelles (Belgium). Unite De Biotech, 64: 173-178.

Mathur, A.K., J. Sundaramurthy and C.B. Majumder, 2006. Kinetics of the removal of monochlorobenzene vapour from waste gases using a trickle bed air biofilter. J. Hazardous Mater., 137: 1560-1568. DOI: 10.1016/j.jhazmat.2006.04.042

Miller, M.J. and D.C. Allen, 2004. Transport of hydrophobic pollutants through biofilms in biofilters. Chem. Eng. Sci., 59: 3515-3525. DOI: 10.1016/j.ces.2004 .05.011

NHMRC, 2002. Ambient air quality goals, national health and medical research council.
Qi, B., W.M. Moe and K. Kinney, 2002. Biodegradation of volatile organic compounds by five fungal species. Applied Microbiol. Biotechnol., 58: 684689. DOI: $10.1007 / \mathrm{s} 00253-002-0938-3$

Rao, C.S., 2007. Environmental pollution control engineering. 2nd dn., New Age International, New Delhi, ISBN-10: 812241835X, pp: 442.

Sidkar, S. and R. Irvine, 1998. Biofilters in Practice. In: Bioremediation, Leson, G. (Ed.), Technomic Publishing, Lancaster, PA, USA.

Song, J. and K.A. Kinney, 1999. Biomass Distribution in a Vapor Phase Bioreactor for Toluene Removal. 1st Edn., Battelle Press, Columbus, Ohio, USA.

Swanson, W. and R. Loehr, 1997. Biofiltration: Fundermentals design and operations principles and applications. J. Environ. Eng., 123: 538-546. DOI: 10.1061/(ASCE)0733-9372(1997)123:6(538)

Tchobanoglous, G. and F. Kreith, 2002. Handbook of Solid Waste Management. 2nd Edn., McGraw-Hill, New York, ISBN-10: 9781601196736, pp: 950.

VanGroenestijn, J.W. and J.X. Liu, 2002. Removal of alpha-pinene from gases using biofilters containing fungi. Atmospheric Environ., 36: 5501-5508. DOI: 10.1016/ S1352-2310(02)00665-9

VanLith, C., G. Leson and R. Michelson, 1997. Evaluating design options for biofilters. J. Air Waste Manage. Assoc., 47: 37-48. DOI: DOI: $10.1080 / 10473289.1997 .10464410$

Veiga, M.C., M. Fraga, L. Amor and C. Kennes, 1999. Biofilter performance and characterization of a biocatalyst degrading alkylbenzene gases. Biodegradation, 10: 169-173. DOI: 10.1023/A:1008301415192

Wieczorek, A., 2005. Pilot-scale biofiltration of waste gases containing aliphatic and aromatic hydrocarbons, phenol, cresols and other volatile organic compounds. Environ. Progress, 24: 60-66. DOI: $10.1002 /$ ep.10037

Woertz, J.R., W.N.M.V. Heiningen, M.H.A.V. Eekert, N.J.R. Kraakman and K.A. Kinney et al., 2002. Dynamic bioreactor operation: Effects of packing material and mite predation on toluene removal from off-gas. Applied Microbiol. Biotechnol., 58: 690694. DOI: 10.1007/s00253-002-0944-5

Yang, C., H. Chen, G. Zeng, G. Yu and S. Lou, 2010. Biomass accumulation and control strategies in gas biofiltration. Biotechnol. Adv., 28: 531-540. DOI: 10.1016/j.biotechadv.2010.04.002

Zappi, M.E., B.C. Fleming and M.J. Cullinane, 1992. Treatment of contaminated groundwater using chemical oxidation. Proceedings of the ASCE Water Forum Conference, (WFC' 92), Baltimore, MD.

Zhang, X.Q. and P.L. Bishop, 2003. Biodegradability of biofilm extracellular polymeric substances. Chemosphere, 50: 63-69. DOI: 10.1016/S00456535(02)00319-3 